\title{
Clinical profile of endometrial histopathological patterns in Abnormal Uterine Bleeding
}

\author{
Sapna Chauhan, Krishnapriya Radhakrishnan \\ Department of Obstetrics and Gynecology, \\ K S Hegde Medical Academy, Mangaluru, Karnataka, India
}

Received: March 10, 2020

Accepted: May 5, 2020

\begin{abstract}
Aims: To study the association of clinical profile of patients with Abnormal Uterine Bleeding with the different endometrial histopathological patterns

Methods: A retrospective cross-sectional study was done in the department of Obstetrics and Gynaecology at a hospital in Karnataka, India from January 2017 to January 2019. Medical records were reviewed for all the cases of abnormal uterine bleeding who underwent endometrial biopsy.

Results: There were 148 records of endometrial biopsies; $>55 \%$ were in $41-50$ years age group; $28 \%$ had postmenopausal bleeding; and $28 \%$ presented with menorrhagia. Menorrhagia and menometrorrhagia were equally common under 50 years of age. The various physiological patterns of endometrium (proliferative, secretory \& menstruating endometrium) were noted in more than half the cases (51\%). Proliferative endometrium was in $37 \%$, followed by hyperplasia without atypia in $22 \%$ and only $3 \%$ showed malignancy; all of whom were in the postmenopausal group. Even in women with post menopausal bleeding, proliferative pattern was the commonest (33\%), followed by atrophic endometrium and malignancy. Atypical hyperplasia was found to be most commonly associated with post menopausal bleeding.
\end{abstract}

Conclusions: Both physiological and non physiological endometrial patterns were seen almost equally among the AUB cases. The knowledge of endometrial pattern in a case of AUB helps to decide a plan of management. Endometrial sampling plays a very important role in management of AUB, especially in the age group of more than $40 \mathrm{yrs}$; i.e, the peri and post-menopausal age groups, where incidence of malignant or pre malignant conditions was noted to be the highest.

Key words: abnormal uterine bleeding, endometrial cancer, endometrial sampling, hyperplasia

Citation : Chauhan S, Radhakrishnan K. Clinical profile of endometrial histopathological patterns in Abnormal Uterine Bleeding. Nep J Obstet Gynecol. 2020;15(30):50-54. DOI: 10.3126/njog.v15i1.29341

\section{INTRODUCTION}

Abnormal uterine bleeding (AUB) is defined as bleeding from the uterine corpus that is abnormal in regularity, volume, frequency or duration and occurs in the absence of pregnancy. ${ }^{1}$ AUB is the most common reason for gynaecological referrals. ${ }^{2}$ The prevalence varies in each country and is reported to occur in about $9-14 \%$ of women. ${ }^{3}$ The PALM-COEIN classification, introduced in 2011 by the International Federation of Gynaecology and Obstetrics (FIGO) standardizes the classification and nomenclature of AUB. ${ }^{4}$ As it specifies the characteristics of normal and abnormal limits of menstruation, it helps

\section{CORRESPONDENCE}

Dr Krishnapriya Radhakrishnan

Department of Obstetrics and Gynecology,

K S Hegde Medical Academy, Mangaluru, Karnataka, India

Email: kpriya252003@yahoo.co.in; Mobile: +91-9008416076 in standardization in the management of AUB. Endometrial carcinoma is the one of the commonest gynaecological malignancies and its precursor, endometrial hyperplasia, usually presents with AUB. ${ }^{5}$ Endometrial hyperplasia is estimated to have at least three times higher incidence than endometrial cancer and hence if detected early, we can prevent many women from developing endometrial carcinoma. ${ }^{6}$ Endometrial sampling, an important tool in the evaluation of AUB, has been recommended by FOGSI $^{3}$ in age $>40$ years; and even at $<40$ years if there is high risk for developing endometrial cancer such as irregular bleeding, obesity associated with hypertension, diabetes, PCOS, endometrial thickness 
$>12 \mathrm{~mm}$, HNPCC, significant family history of malignancy, tamoxifen usage, AUB not responding to medical treatment. Though transvaginal ultrasound aids in suspecting endometrial hyperplasia, the diagnosis requires histological examination of the endometrial tissue. Hysteroscopy combined with guided biopsy is more accurate than dilatation and curettage. ${ }^{5,7}$ This study aims to find out the clinical and histopathological profile of patients with AUB.

\section{METHODS}

This is a retrospective study of medical records of all cases of abnormal uterine bleeding with endometrial biopsies in two years from January 2017 to January 2019 at Department of Obstetrics and Gynecology of K S Hegde Medical Academy, Mangaluru, Karnataka, India. Women with pregnancy complications were excluded from the study. Descriptive analysis was performed.

\section{RESULTS}

There were 148 women who underwent endometrial biopsy for AUB. The most common menstrual complaints for which endometrial sampling was performed included post menopausal bleeding (28\%), menorrhagia (28\%) and irregular and heavy menstrual bleeding (26\%) [Figure-1].

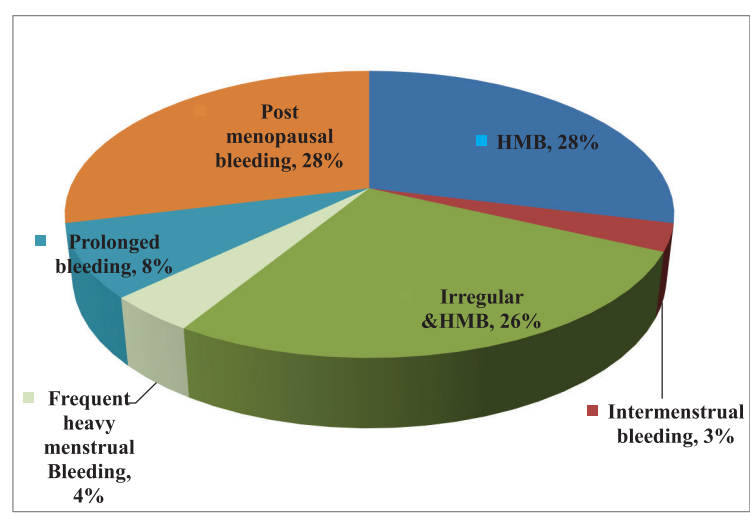

Figure-1: Menstrual complaints in the study population $(n=148)$

Maximum patients for whom endometrial sampling was done were in the 41-50 yrs age group. Only two patients were subjected to sampling in the $<30 \mathrm{yrs}$ age group [Figure-2].

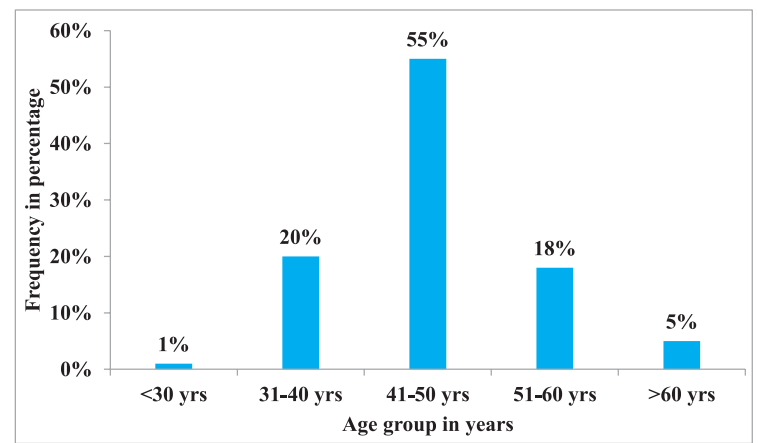

Figure-2: Age distribution of the study population $(\mathrm{n}=148)$

Half of samples had normal pattern of endometrium like menstrual, proliferative and secretary; and only $3 \%$ had malignant pathology and they were all in postmenopausal age group [Figure-3].

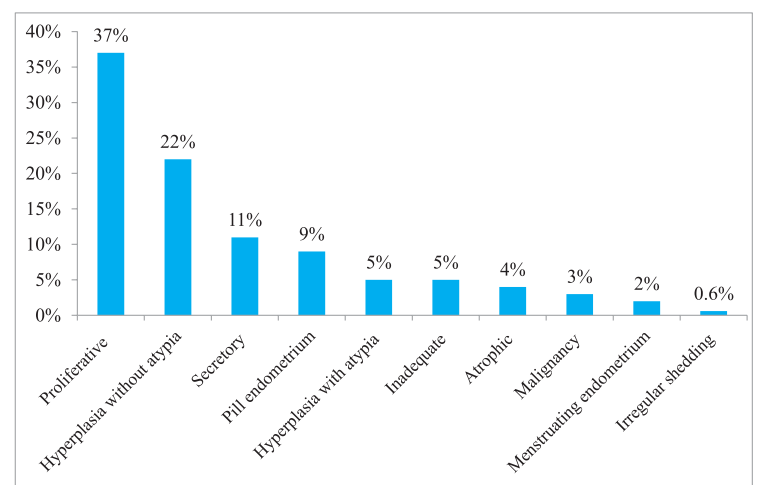

Figure-3: Histopathological pattern of endometrial biopsies $(\mathrm{n}=148)$

In all the age groups (except $>60 \mathrm{yrs}$ ), the commonest pattern was proliferative endometrium [Figure-4].

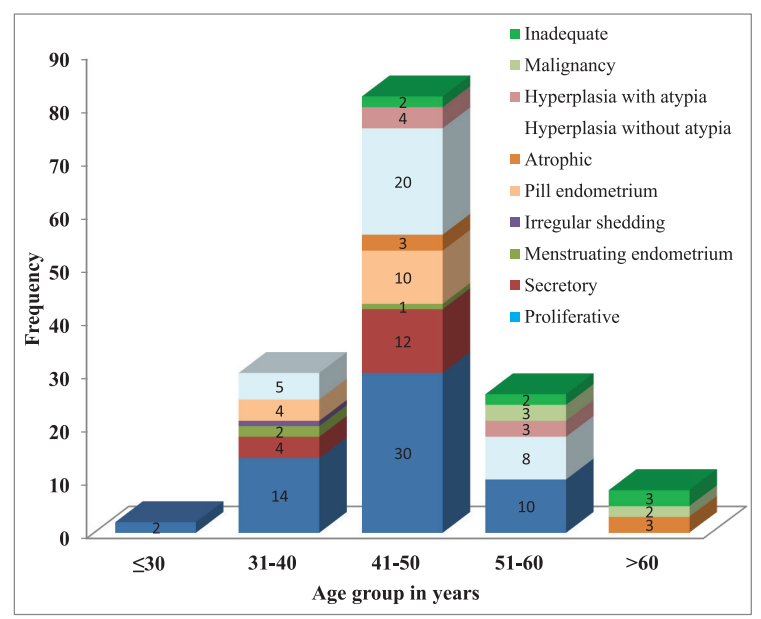

Figure-4: Endometrial pattern by age group

Menorrhagia and metrorrhagia were equally distributed at $<30$ years of age; and these were the 
commonest indications of biopsy under 50 years of age [Figure-5].

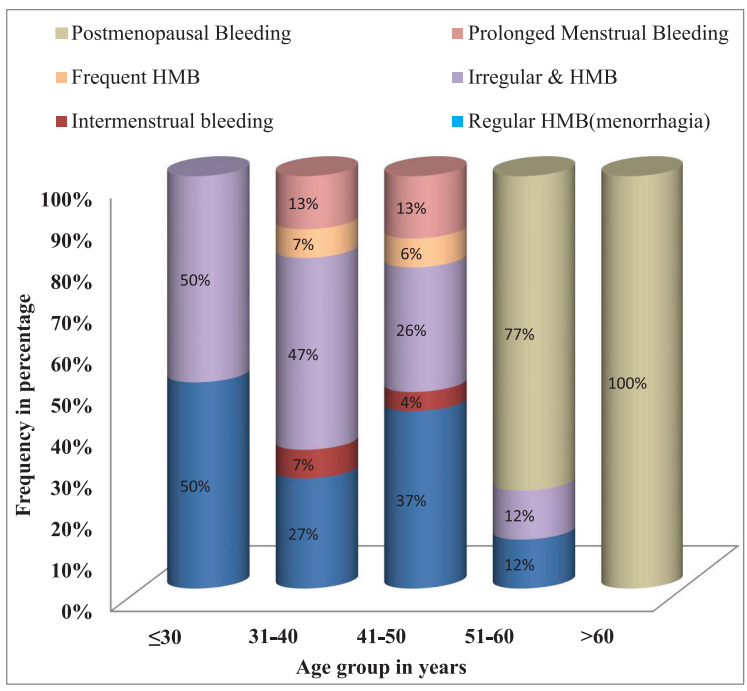

In the present study, among patients with menorrhagia/ heavy menstrual bleeding with regular cycles, functional endometrium was noted to be the commonest pattern - proliferative pattern was seen in $38 \%$ cases and secretory in $24 \%$ cases. In patients with irregular cycles with heavy menstrual bleeding, proliferative endometrium was the commonest pattern, seen in $49 \%$ cases followed by endometrial hyperplasia without atypia seen in $23 \%$ cases. In women who presented with post menopausal bleeding, 'proliferative endometrium' was noted to be the most common pattern $(33 \%)$ followed by 'hyperplasia without atypia' (19\%) and 12\% each were malignancy and atrophic endometrium. All cases of malginancy had presented with post menopausal bleeding [Table-1].

Figure-5: Bleeding pattern by age group

Table-1: Endometrial histopathology in different clinical bleeding patterns

\begin{tabular}{|c|c|c|c|c|c|c|c|c|c|c|c|}
\hline Bleeding Pattern & 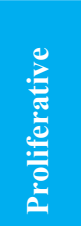 & 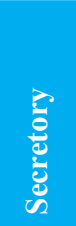 & 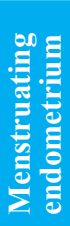 & 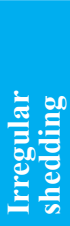 & 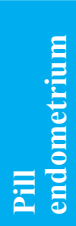 & $\frac{\mathscr{E}}{\frac{\mathscr{E}}{\overparen{E}}}$ & 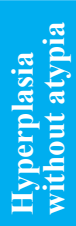 & 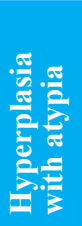 & 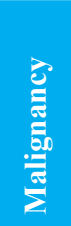 & 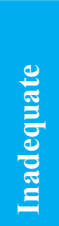 & $\Sigma$ \\
\hline Regular \& HMB & $38 \%$ & $24 \%$ & - & - & $17 \%$ & - & $14 \%$ & $5 \%$ & - & $2 \%$ & $100 \%$ \\
\hline Intermenstrual bleeding & $40 \%$ & - & - & - & - & - & $40 \%$ & $20 \%$ & - & - & $100 \%$ \\
\hline Irregular \& HMB & $49 \%$ & $8 \%$ & $8 \%$ & & $10 \%$ & $3 \%$ & $23 \%$ & - & - & - & $100 \%$ \\
\hline Frequent menstrual bleeding & $43 \%$ & $14 \%$ & - & - & - & - & $43 \%$ & - & - & - & $100 \%$ \\
\hline Prolonged menstrual bleeding & $15 \%$ & $8 \%$ & & $8 \%$ & $23 \%$ & & $38 \%$ & $8 \%$ & - & - & $100 \%$ \\
\hline Post menopausal bleeding & $33 \%$ & $2 \%$ & - & - & - & $12 \%$ & $19 \%$ & $7 \%$ & $12 \%$ & - & $100 \%$ \\
\hline
\end{tabular}

Maximum patients (63\%) had a parity score of 2 and above. Though nulliparity is considered a risk factor for endometrial hyperplasia/malignancy, all five malignancy cases were mutiparous women probably because the number of nulliparous women in the study were less [Table-2].

Table-2: Endometrial histopathology by parity

\begin{tabular}{|l|c|c|c|c|}
\hline \multicolumn{1}{|c|}{ Histopathology } & $\begin{array}{c}\text { Para } \\
-\mathbf{0}\end{array}$ & $\begin{array}{c}\text { Para } \\
\mathbf{- 1}\end{array}$ & $\begin{array}{c}\text { Para } \\
\mathbf{- 2}\end{array}$ & $\begin{array}{c}\text { Para } \\
\mathbf{2}\end{array}$ \\
\hline Proliferative & 4 & 6 & 23 & 23 \\
\hline Secretory & - & 2 & 8 & 6 \\
\hline Menstruating endometrium & - & - & 1 & 2 \\
\hline Irregular shedding & - & - & 1 & - \\
\hline Pill endometrium & - & 3 & 7 & 4 \\
\hline
\end{tabular}

\begin{tabular}{|l|c|c|c|c|}
\hline \multicolumn{1}{|c|}{ Histopathology } & $\begin{array}{c}\text { Para } \\
\mathbf{- 0}\end{array}$ & $\begin{array}{c}\text { Para } \\
\mathbf{- 1}\end{array}$ & $\begin{array}{c}\text { Para } \\
\mathbf{- 2}\end{array}$ & $\begin{array}{c}\text { Para } \\
\mathbf{\geq 3}\end{array}$ \\
\hline Atrophic & - & - & 2 & 4 \\
\hline Hyperplasia without atypia & 4 & 5 & 17 & 7 \\
\hline Hyperplasia with atypia & 1 & 1 & 1 & 4 \\
\hline Malignancy & - & - & 1 & 4 \\
\hline Inadequate & 1 & 1 & 2 & 3 \\
\hline
\end{tabular}

Only $77(52 \%)$ patients underwent hysteroscopy at the time of endometrial sampling. Fifteen cases also underwent polypectomy at the time of endometrial sampling of which seven were associated with proliferative endometrium, three cases with 'endometrial hyperplasia without atypia', two with 'endometrial hyperplasia with atypia' cases and one 
case each with malignancy, secretory endometrium and pill endometrium

In patients with post menopausal bleeding, endometrial thickness (ET) varied from $4 \mathrm{~mm}$ to $40 \mathrm{~mm}$. Since the endometrial thickness was not documented in some of the cases, we could not study the association of ET with the different histological patterns. All the 5 cases of AUB diagnosed with endometrial malignancy presented with post menopausal bleeding and had ET of more than $10 \mathrm{~mm}$

\section{DISCUSSION}

The incidence of endometrial pathologies like hyperplasia and malignancy was found to be a little higher in our study than other recently conducted similar studies..$^{8-14}$

Junu Devi et $\mathrm{al}^{8}$ found much more atrophic cases than this study in 500 cases; Alpana Singh et $\mathrm{al}^{9}$ found similar findings except higher cases having secretory endometrium in 300 cases; Gon S et al ${ }^{10}$ reported more atrophic endometrium like Junu Devi et $\mathrm{al}^{8}$ in 156 cases; Rawat et $\mathrm{al}^{11}$ reported 50\% having physiological change and less hyperplasia in 206 cases; Sajeetha et $\mathrm{al}^{12}$ reported similar findings except lower number of proliferative endometrium in 217 cases; Bindroo $\mathrm{S}$ et $\mathrm{al}^{13}$ found more secretory phase endometrium, more than $70 \%$ as physiological changes and malignancy was less in 250 cases; Neha Batra et $\mathrm{al}^{14}$ reported less number of hyperplasia in 200 cases [Table-3].

Table 3- Comparison of endometrial patterns in various studies

\begin{tabular}{|c|c|c|c|c|c|c|c|c|}
\hline $\begin{array}{c}\text { Endometrial } \\
\text { pattern }\end{array}$ & $\begin{array}{l}\text { Present } \\
\text { study } \\
(\mathrm{N}=\mathbf{1 4 8})\end{array}$ & $\begin{array}{c}\text { Junu devi } \\
\text { et }^{\mathbf{l}^{8 *}} \\
\mathbf{2 0 1 4} \\
(\mathbf{N}=\mathbf{5 0 0})\end{array}$ & $\begin{array}{c}\text { Alpana } \\
\text { singh et al } \\
2016 \\
(\mathbf{N}=300)\end{array}$ & $\begin{array}{c}\text { Gon } S \text { et } \\
\text { al }^{10} \\
2016 \\
(\mathrm{~N}=156)\end{array}$ & $\begin{array}{c}\text { Rawat et } \\
\text { al } \\
2016 \\
(\mathrm{~N}=206)\end{array}$ & $\begin{array}{c}\text { Sajitha et } \\
\text { al }^{12} \\
2017 \\
(\mathrm{~N}=217)\end{array}$ & $\begin{array}{c}\text { Bindroo } S \\
\text { et }^{1 l^{13}} \\
2018 \\
(\mathrm{~N}=\mathbf{2 5 0})\end{array}$ & $\begin{array}{c}\text { Neha } \\
\text { Batra et } \\
\text { al }^{14} \\
(\mathbf{N}=\mathbf{2 0 0})\end{array}$ \\
\hline Proliferative & $37.8 \%$ & $25.4 \%$ & $37 \%$ & $15.3 \%$ & $29.4 \%$ & $12.2 \%$ & $37.2 \%$ & $30 \%$ \\
\hline Secretory & $10.8 \%$ & $4.6 \%$ & $30 \%$ & $33 \%$ & $19.9 \%$ & $16.7 \%$ & $34 \%$ & $15 \%$ \\
\hline Hyperplasia & $26.7 \%$ & $18.8 \%$ & $22.6 \%$ & $5.7 \%$ & $6.1 \%$ & $25 \%$ & $16 \%$ & $8 \%$ \\
\hline Atrophic & $4 \%$ & $36.2 \%$ & $3 \%$ & $16 \%$ & $4.2 \%$ & $5.12 \%$ & $7.2 \%$ & $3.5 \%$ \\
\hline Malignancy & $3.3 \%$ & $0.6 \%$ & $1 \%$ & $4.4 \%$ & $0.98 \%$ & $6.3 \%$ & $0.8 \%$ & $1.5 \%$ \\
\hline
\end{tabular}

*Study done in 40-60 yrs age group

As a presentation this study found less number of menorrhagia than other studies ${ }^{8,9,10,13}$; metrorrhagia was almost similar to the studies ${ }^{9,10,13}$ except the study done by Alpana singh et $\mathrm{al}^{9}$ our study $\mathrm{y}^{8,9,10,13}$ had lower incidence of polymenorrhoea; but postmenopausal bleeding was much higher [Table-4].

Table-4: Comparison of menstrual complaints in various studies

\begin{tabular}{|c|c|c|c|c|c|}
\hline 㿣 & 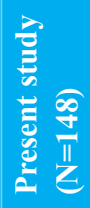 & 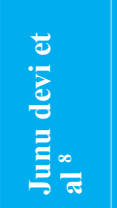 & 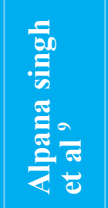 & 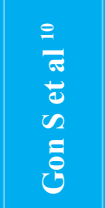 & 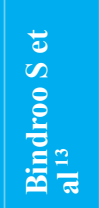 \\
\hline Menorrhagia & $28 \%$ & $68.8 \%$ & $42 \%$ & $42.9 \%$ & $51 \%$ \\
\hline $\begin{array}{l}\text { Metrorhagia/ } \\
\text { menometrorhagia }\end{array}$ & $29 \%$ & $20.39 \%$ & $15.2 \%$ & $32.6 \%$ & $19 \%$ \\
\hline polymenorrhea & $4 \%$ & $6.65 \%$ & $15 \%$ & $8.9 \%$ & $11 \%$ \\
\hline $\begin{array}{l}\text { Post menopausal } \\
\text { bleeding }\end{array}$ & $28 \%$ & $2.15 \%$ & $8.6 \%$ & $15.3 \%$ & $13.6 \%$ \\
\hline
\end{tabular}

Younger age group (less than 30 years) was far less than the study of Rawat et al ${ }^{11}$ and Bindroo $\mathrm{S}$ et al ${ }^{13}$, and age over 50 was more in comparison to the studies done by Alpana singh et al ${ }^{9}$, Rawat et al ${ }^{11}$ and Bindroo S et al ${ }^{13}$ but Junu devi et $\mathrm{al}^{8}$ had taken all cases over 40 years of age [Table-5].

Table-5: Comparison of age groups in various studies

\begin{tabular}{|c|c|c|c|c|c|}
\hline 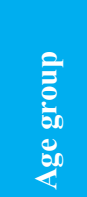 & 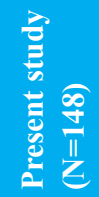 & 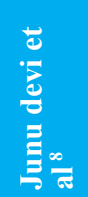 & 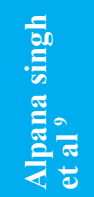 & 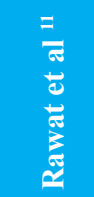 & 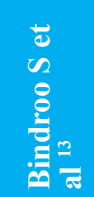 \\
\hline$<30$ & $1.3 \%$ & & $5.3 \%$ & $35.2 \%$ & $13.2 \%$ \\
\hline $31-40$ & $20.2 \%$ & & $36.3 \%$ & $21.8 \%$ & $30.4 \%$ \\
\hline $41-50$ & $55.4 \%$ & \multirow{2}{*}{$100 \%$} & $48.6 \%$ & $35.9 \%$ & $43.2 \%$ \\
\hline$>50$ & $22.9 \%$ & & $9.6 \%$ & $6.8 \%$ & $13.2 \%$ \\
\hline
\end{tabular}

Parity distribution of study cases was proportional to the study done by Alpana singh et $\mathrm{al}^{9}$ but more than $50 \%$ were of three or more parity in the study of 
Bindroo S et al ${ }^{13}[$ Table-6].

Table-6: Comparison of parity in various studies

\begin{tabular}{|c|c|c|c|}
\hline Parity & $\begin{array}{c}\text { Present study } \\
(\mathbf{N}=148)\end{array}$ & $\begin{array}{c}\text { Alpana singh } \\
\text { et al }{ }^{\text {14 }}\end{array}$ & $\begin{array}{c}\text { Bindroo S } \\
\text { et al }{ }^{13}\end{array}$ \\
\hline 0 & $6.7 \%$ & $8 \%$ & $7.6 \%$ \\
\hline 1 & $12.1 \%$ & $17.6 \%$ & \\
\hline 2 & $42.5 \%$ & $35.3 \% \%$ & $14.8 \%$ \\
\hline$\geq 3$ & $38.5 \%$ & $39 \%$ & $>50 \%$ \\
\hline
\end{tabular}

In the present study, the incidence of pathological causes of AUB (hyperplasia and malignancy) was $30 \%$, slightly higher than the other studies, indicating the significance of endometrial sampling in our population. Endometrial sampling is required to ensure that malignancies and pre malignant conditions are picked up early, especially in the age group of more than 40 years to improve the patient's outcome. We have also studied the association of the different endometrial patterns with age, menstrual complaints $\&$ parity. Patients with post menopausal bleeding and irregular cycles were found to be more commonly associated have significant endometrial pathologies

\section{CONCLUSIONS}

The incidence of endometrial pathologies like hyperplasia and malignancy was found to be a little higher. Menorrhagia and metrorrhagia were the main indications of biopsy under 50 years of age. The maximum cases of hyperplasia were seen in post menopausal bleeding and all malignant cases were in this age group.

\section{REFERENCES}

1. Munro MG, Critchley HO, Broder MS, Fraser IS. FIGO classification system (PALM-COEIN) for causes of abnormal uterine bleeding in nongravid women of reproductive age. FIGO Working Group on Menstrual Disorders. Int J Gynaeco Obstet. 2011;113:3-13

2. H van Dongen, CD de Kroon, CE Jacobi, JB Trimbos, FW Jansena. Diagnostic hysteroscopy in abnormal uterine bleeding: a systematic review and meta-analysis. BJOG 2007; 114:664-75

3. FOGSI. Management guidelines of Abnormal Uterine Bleeding in reproductive period- evidence based good clinical practice recommendations for Indian women. 2016

4. Diagnosis of abnormal uterine bleeding in reproductiveaged women. Practice Bulletin No. 128. American College of Obstetricians and Gynecologists. Obstet Gynecol. 2012;120:197-206.

5. RCOG Green top guideline no. 67 , management of endometrial hyperplasia. 2016.

6. Reed SD, Newton KM, Clinton WL, Epplein M, Garcia R, Allison K, et al. Incidence of endometrial hyperplasia. Am J Obstet Gynecol. 2009;200:678:1-6.

7. Gimpelson RJ, Rappold HO. A comparative study between panoramic hysteroscopy with directed biopsies and dilatation and curettage -A review of 276 cases. Am J Obstet Gynecol. 1988;158 (3 Pt 1):489-92.
8. Junu Devi, Aziz N. Study of histopathological pattern of endometrium in abnormal uterine bleeding in the age group 40-60 years -a study of 500 cases. Int J Med Sci Clinical Inventions. 2014;1(10):579-85.

9. Alpana Singh, P.V. Ramana Bai. Study of histopathological pattern of endometrium in abnormal uterine bleeding and its management. Int J Reprod Contracep Obstet Gynecol. 2016;5(2):432-6

10. Gon S, Tamalika K, Mallick D, Ghosh G. A study on histopathological patterns of endometrium in different types of abnormal uterine bleeding among periand postmenopausal women. J Dent Med Sci. 2016;15(9):106-11.

11. Rawat K, Rawat N, Mathur N, Mathur M. Histopathological study of endometrium in abnormal uterine bleeding. Am Int J Res Formal Applied Nat Sci. 2017;19(1):18-20.

12. Sajeetha KR, Anuradha M. Endometrial patterns in abnorma uterine bleeding: a retrospective study. Int J Reprod Contracep Obstet Gynecol. 2017;6(11):4966-70.

13. Simridhi Bindroo, Monika Garg, Tajinder Kaur. Histopathological spectrum of endometrium in abnormal uterine bleeding. Int J Reprod Contracept Obstet Gynecol. 2018;7(9):3633-

14. Neha Batra N, Chaudhari S, Hatwal D. Histopathologica variations in endometrial biopsies. Int J Med Health Res. 2019;5(1):229-32 